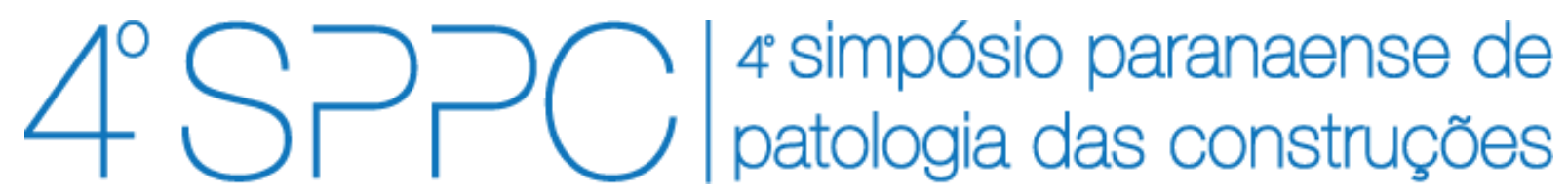

ISSN 2526-7248 artigo n. 4SPPC113, pp. 101-111, 2019

\title{
Avaliação do comportamento de resinas epoxídicas submetidas a ciclos de umidade
}

\author{
Dalfré, Gláucia M. '; Oliveira, Matusalém C. ${ }^{2}$; Sarti Júnior, Luiz A. ${ }^{3}$; Araújo, Ciro J. V. ${ }^{4}$ \\ ${ }_{1}^{1}$ PhD, PPGECiv, Universidade Federal de São Carlos, glaucia.dalfre@ufscar.br \\ ${ }^{2}$ Mestre, PPGECiv, Universidade Federal de São Carlos, matusa00@gmail.com \\ ${ }^{3}$ Mestrando, PPGECiv, Universidade Federal de São Carlos, luiz.sarti.junior@gmail.com \\ ${ }^{2}$ Mestre, Instituto de Pesquisas Tecnológicas de São Paulo (IPT), ciroaraujo@ipt.br
}

Resumo: Um programa experimental de longa duração encontra-se em andamento e tem por objetivo a análise do comportamento de resinas epoxídicas utilizadas em sistemas de reforço de estruturas e aplicadas segundo a técnica Externally Bonded Reinforcement (EBR). Neste sentido, corpos de prova de resinas foram moldados e, após 14 dias de idade, mantidos em ambiente protegido ou expostos a ciclos de umidade e posteriormente ensaiados nas idades de 4,8 e 12 meses. A resina A (primer) apresentou redução da tensão de tração e módulo de elasticidade de até $74 \%$ e $69 \%$, respectivamente, quando comparado aos resultados obtidos nos ensaios realizados aos 14 dias (referência). Para além disso, verificou-se o amolecimento da matriz para a idade de 8 meses. A resina B (laminação) apresentou reduções de até $51 \%$ e $43 \%$ da tensão máxima e módulo de elasticidade, respectivamente, quando exposta a ciclos de umidade.

Palavras-chave: Degradação; durabilidade; resinas epoxídicas; ciclos de umidade

Abstract: A long-term ongoing experimental program aims to analyze the behavior of epoxy resins used for the strengthening of structures applied according to the Externally Bonded Reinforcement (EBR) technique. In this sense, specimens of epoxy resin were molded and, with 14 days age, maintained in a protected environment or exposed to humidity cycles and subsequently tested at ages of 4,8 and 12 months. The resin A (primer) showed a reduction of the tensile strength and modulus of elasticity of up to $74 \%$ and $69 \%$, respectively, when compared to the results obtained in the tests carried out at 14 days (reference). In addition, a matrix softening was observed at 8 months age. Resin B (lamination) presented reductions of up to $51 \%$ and $43 \%$ of the maximum stress and modulus of elasticity, respectively, when exposed to moisture cycles.

Keywords: Degradation; durability; epoxy resins; humidity cycles 


\section{Introdução} artigo 4SPPC113, pp. $101-111$, 2019. DOI: 10.4322/2526-7248.033

Nos últimos anos os Polímeros Reforçados com Fibras (PRF, ou FRP - Fiber Reinforced Polymer, em língua inglesa) têm sido amplamente aplicados em obras da engenharia civil para reforço de estruturas devido às suas diversas vantagens em relação aos materiais concreto ou aço tais como a relação de alta resistência/peso, resistência à corrosão e fácil instalação. Segundo Hollaway [1], os FRPs são formados a partir da combinação de fibras (de carbono, vidro ou aramida, por exemplo) em uma matriz, formando um novo material (Figura 1). Segundo Machado e Machado [2], as fibras são responsáveis por proporcionar resistência e rigidez, enquanto a matriz é responsável por unir fibras e formar uma barreira de proteção contra os ataques dos agentes agressores ambientais.

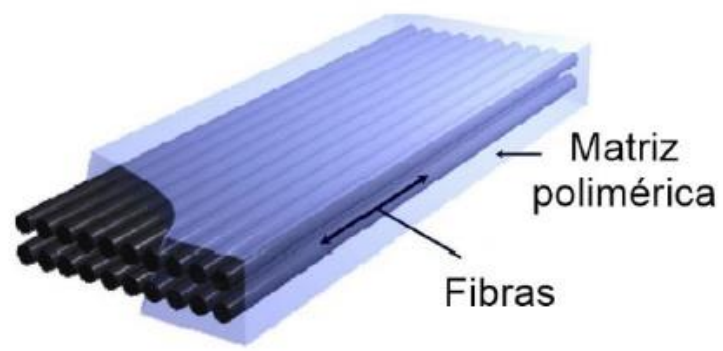

Figura 1: Composição do FRP (ISIS [3])

Atualmente, a maior parte das aplicações dos compósitos de FRP se dá por meio do uso da técnica EBR, na qual se utiliza uma resina do tipo epóxi para garantir a união entre o material de reforço e o substrato de concreto. Disponível no mercado em forma de bicomponente (monômero e catalisador), o adesivo epoxídico, quando misturado, permanece em estado viscoso por um curto período (pot-life), posteriormente endurecendo e passando para um estado sólido, quando então atinge boas propriedades mecânicas (SOUZA e RIPPER [4]).

Dentre as técnicas de reforço com FRPs citam-se a Externally Bonded Reinforcement (EBR), a qual consiste na colagem externa de mantas ou laminados de FRP no substrato de concreto, e a Near Surface Mounted, a qual baseia-se na inserção de barras ou laminados em entalhes efetuados no concreto de cobrimento do concreto. Note-se que resinas epoxídicas são utilizadas, em ambas as técnicas, para colagem do material de reforço ao elemento estrutural.

$\mathrm{Na}$ técnica EBR as resinas permanecem desprotegidas e susceptíveis às ações ambientais. Nesse sentido, o desafio atual para os engenheiros civis está relacionado a questões que envolvem o comportamento ao longo do tempo e a durabilidade do sistema de reforço, principalmente quando exposto a condições ambientais agressivas, as quais que podem atuar individualmente ou em conjunto na degradação do compósito de FRP (Silva [5]). Os fatores considerados mais críticos para a durabilidade dos sistemas de reforço em FRP são apresentados na Figura 2 (ISIS [3]). 
DALFRÉ, G. M.; OLIVEIRA, M. C.; SARTI JR., L. A; ARAÚJO, C. J. V. AVALIAÇÃO DO COMPORTAMENTO DE RESINAS EPOXÍDICAS SUBMETIDAS A CICLOS DE UMIDADE. $4^{\circ}$ Simpósio Paranaense de Patologia das Construções (4 SPPC), artigo 4SPPC113, pp. $101-111$, 2019. DOI: 10.4322/2526-7248.033

Diante disso, diversas pesquisas têm sido realizadas a fim de se obter um melhor entendimento sobre os efeitos causados pelos fatores ambientais na durabilidade da ligação concreto/adesivo/FRP e no comportamento dos elementos estruturais reforçados em longo prazo, as quais serão breviamente apresentadas.

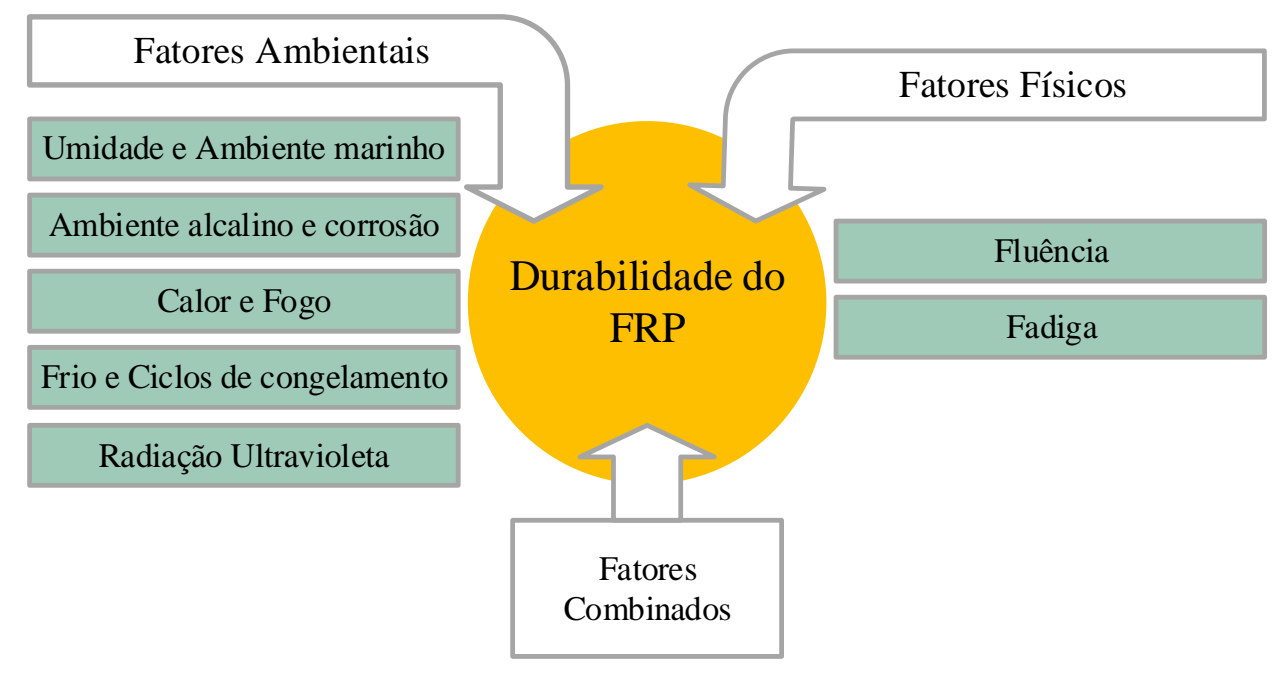

Figura 2: Fatores que afetam a durabilidade dos compósitos de FRP (ISIS [4]).

\section{Influência da umidade no comportamento de resinas expostos à umidade}

Por serem resistentes à corrosão eletroquímica, os materiais compósitos de FRP geralmente são empregados em forma de armadura ou reforço em estruturas de concreto que se encontram em ambientes úmidos e marinhos, nos quais a corrosão do sistema tradicional contendo armaduras metálicas resultaria em degradação severa da estrutura (ISIS [3]).

Entretanto, apesar de resistentes à corrosão eletroquímica, estes materiais não estão completamente imunes aos danos causados pela umidade, uma vez que a água é absorvida por todos os tipos de polímeros orgânicos modificando suas características termofísicas, mecânicas e químicas (ISIS [3]; Helbling e Karbhari [6]).

Para Weitsman e Elahi [7], o processo de absorção de umidade por compósitos poliméricos e seus efeitos nas propriedades mecânicas do material são questões bastante complexas, embora saiba-se que existe uma relação entre a taxa de degradação do FRP e a taxa de absorção de umidade pela matriz polimérica. Essa taxa de absorção ainda pode ser modificada por outras condições de exposição atuando simultaneamente, assim, uma elevação nos níveis de tensão aplicados e na temperatura aumenta a taxa de absorção de umidade do FRP (ISIS [3]).

A absorção de umidade pela resina resulta primeiramente em amolecimento da matriz, ou seja, ocorre um aumento da mobilidade molecular da matriz polimérica uma vez que as moléculas de água ocupam os espaços entre as cadeias poliméricas, reduzindo as forças coesivas intermoleculares. Este é um processo reversível que resulta em redução da temperatura de transição vítrea $\left(T_{g}\right)$, a qual é a temperatura acima da qual as propriedades 
DALFRÉ, G. M.; OLIVEIRA, M. C.; SARTI JR., L. A; ARAÚJO, C. J. V. AVALIAÇÃO DO COMPORTAMENTO DE RESINAS EPOXÍDICAS SUBMETIDAS A CICLOS DE UMIDADE. $4^{\circ}$ Simpósio Paranaense de Patologia das Construções (40 SPPC), artigo 4SPPC113, pp. $101-111$, 2019. DOI: 10.4322/2526-7248.033

mecânicas do polímero mudam de um sólido rígido e frágil para as de um plástico fluido e viscoso. No caso de exposição à umidade por um longo período de tempo, ocorre simultaneamente a hidrólise, um ataque às ligações químicas da resina, modificando irreversivelmente sua estrutura química e reduzindo a sua $T_{g}$ (Ghorbel e Valentim [8]).As matrizes poliméricas geralmente são consideradas estruturalmente ineficientes em temperaturas superiores à temperatura de transição vítrea. Dessa forma, o enfraquecimento das ligações intermoleculares dos polímeros resulta em redução da sua resistência, módulo de elasticidade, deformação máxima e dureza (ISIS [3]).

Pesquisa realizada por Yang et al. [9] avaliou o efeito da imersão de resinas epoxídicas em água por 24 meses (em temperatura constante de $23^{\circ} \mathrm{C}, 38^{\circ} \mathrm{C} \mathrm{e} 60^{\circ} \mathrm{C}$ ). Os resultados da pesquisa indicam uma pequena redução da $T_{g}$ para as amostras mantidas à $23^{\circ} \mathrm{C}$ e uma redução mais expressiva para as amostras mantidas à $38^{\circ} \mathrm{C}$ e $60^{\circ} \mathrm{C}$. Além disso foram constatadas reduções nas propriedades mecânicas das amostras de resina obtendo-se, ao fim dos 24 meses, reduções na resistência à tração de $43 \%$, 44\% e $69 \%$ e reduções no módulo de elasticidade de $36 \%, 40 \%$ e $68 \%$ para as temperaturas de $23^{\circ} \mathrm{C}, 38^{\circ} \mathrm{C}$ e $60^{\circ} \mathrm{C}$, respectivamente.

Silva et al. [10] analisaram as propriedades mecânicas de corpos de prova de resina epóxi imersas em água à $20^{\circ} \mathrm{C}$ por 480 dias. Os resultados de ensaios de tração indicaram redução da resistência à tração de $38 \%$ e redução do módulo de elasticidade de $53 \%$.

Pesquisa realizada por Abanilla et al. [12] também avaliou as propriedades mecânicas de compósitos de CFRP e resina epóxi mantidos por 100 semanas imersos em água (em temperatura constante de $23^{\circ} \mathrm{C}, 38^{\circ} \mathrm{C} \mathrm{e} 60^{\circ} \mathrm{C}$ ). Os resultados para o laminado contendo 6 camadas indicaram redução na resistência à tração de 32\%, 39\% e 42\% e no módulo de elasticidade de $12 \%, 22 \%$ e $27 \%$ para as temperaturas de $23^{\circ} \mathrm{C}, 38^{\circ} \mathrm{C}$ e $60^{\circ} \mathrm{C}$, respectivamente. Além disso também foram constatadas reduções na resistência à flexão de $31 \%$, $40 \%$ e $50 \%$ e no módulo de flexão de $9 \%$, $16 \%$ e $28 \%$ para as mesmas temperaturas anteriormente apresentadas.

A umidade também enfraquece a ligação entre o adesivo e o substrato de concreto. A água próxima ou entre a interface adesivo-concreto degrada essa ligação por meio de pressão osmótica, absorção de umidade e amolecimento do adesivo (ISIS [3]).

Pesquisa realizada por Benzarti et al. [12] avaliou a resistência da ligação FRP-concreto por meio de ensaios de arrancamento (pullout). Compósitos de CFRP e resina epoxídica pré-fabricados e laminados manualmente também aplicados segundo a técnica EBR e mantidos por 20 meses em umidade de $95 \%$ e $40^{\circ} \mathrm{C}$. Os resultados deste programa experimental indicaram significativa redução na tensão de arrancamento do FRP (46\% para o laminado manual e $49 \%$ para o laminado pré-fabricado) e também observou-se uma alteração nos modos de ruptura da ligação, passando de coesiva no concreto para adesiva na ligação resina-concreto. 


\section{Programa experimental} artigo 4SPPC113, pp. $101-111$, 2019. DOI: 10.4322/2526-7248.033

Tendo por objetivo a avaliação temporal do comportamento de adesivos estruturais utilizados em sistemas de reforço de estruturas de concreto armado, 520 corpos de prova de resinas epoxídicas [Resina A (saturante) e Resina B (laminação)] foram expostos a diferentes situações:

- Ambiente laboratorial (sala com monitoração de umidade e temperatura constante), sendo que estes serviram como referência aos demais ensaios;

- Exposição às intempéries (em ambiente com umidade e temperatura monitorizados);

- Ciclos de umidade (imersão em água obtida da rede pública de abastecimento por 7 dias), com posterior remoção da água e armazenagem em ambiente com umidade e temperatura controlados; e

- Umidade constante (imersão em água obtida da rede pública de abastecimento e com temperatura controlada).

A Tabela 1 apresenta o resumo da campanha experimental que está sendo realizada para cada tipo de resina/ambiente de exposição.

Tabela 1: Campanha experimental em andamento

\begin{tabular}{|c|c|c|c|}
\hline \multirow[t]{2}{*}{ Ambientes de exposição } & \multirow[t]{2}{*}{ Previsão de ensaio } & \multicolumn{2}{|c|}{$\begin{array}{c}\text { Quantidade de } \\
\text { corpos de } \\
\text { prova/ambiente }\end{array}$} \\
\hline & & Resina A & Resina B \\
\hline \multirow{10}{*}{$\begin{array}{l}\text { - Referência } \\
\text { - Exposição às intempéries } \\
\text { - Ciclos de umidade } \\
\text { - Exposição à umidade }\end{array}$} & 7 dias (cura parcial) & 5 & 5 \\
\hline & 14 dias (cura completa) & 5 & 5 \\
\hline & 4 meses & 5 & 5 \\
\hline & 8 meses & 5 & 5 \\
\hline & 12 meses & 5 & 5 \\
\hline & 2 anos $^{*}$ & 5 & 5 \\
\hline & 3 anos* & 5 & 5 \\
\hline & 4 anos* & 5 & 5 \\
\hline & 5 anos $^{*}$ & 5 & 5 \\
\hline & 10 anos $^{*}$ & 5 & 5 \\
\hline \multicolumn{2}{|c|}{ Total de corpos de prova } & 225 & 225 \\
\hline
\end{tabular}

*Ensaios a serem realizados na continuação do programa experimental

Neste trabalho serão apresentados somente os resultados obtidos até o momento para os corpos de prova mantidos em ambiente laboratorial e ciclos de umidade analisados nas idades de 7 e 14 dias, 4, 8 e 12 meses. Os demais resultados até agora obtidos podem ser encontrados em Ferreira [13] e Oliveira [14]. 
DALFRÉ, G. M.; OLIVEIRA, M. C.; SARTI JR., L. A; ARAÚJO, C. J. V. AVALIAÇÃO DO COMPORTAMENTO DE RESINAS EPOXÍDICAS SUBMETIDAS A CICLOS DE UMIDADE. $4^{\circ}$ Simpósio Paranaense de Patologia das Construções (40 SPPC), artigo 4SPPC113, pp. $101-111$, 2019. DOI: 10.4322/2526-7248.033

O programa experimental em andamento foi dividido nas seguintes etapas:

- Confecção dos corpos de prova de resina epoxídica: A geometria de reprodução dos corpos de prova de resina epoxídica segue as dimensões apresentadas na recomendação ISO 527-2 [16]. As etapas para obtenção dos corpos de prova de resina epoxídica foram mistura mecânica dos componentes das resinas epoxídicas por um tempo mínimo de 3 minutos, de modo a se obter a homogeneização dos materiais; lançamento da mistura nos moldes de teflon; remoção do excesso de resina; desmolde dos corpos de prova com cura mínima de 24 horas; limpeza do molde e preparo para nova moldagem (Figura 3). Algumas vezes bolhas são formadas ao longo do lançamento da resina epoxídica. Assim, corpos de prova com muitas bolhas foram descartados e não utilizados na campanha experimental.

- Exposição aos ambientes pré-definidos: Após o tempo de cura (14 dias), os corpos de prova de resina epoxídica foram expostos aos ambientes previamente apresentados na Tabela 1. Os corpos de prova de resina epoxídica mantidos em ciclos de umidade foram acondicionados em caixas de isopor (em sala com temperatura e umidade monitoradas) e imersos em água da rede pública de abastecimento. A Figura 4a apresenta uma representação dos locais de exposição dos corpos de prova. Os ciclos são compostos por imersão em caixa com água de abastecimento por 7 dias versus secagem por 7 dias.

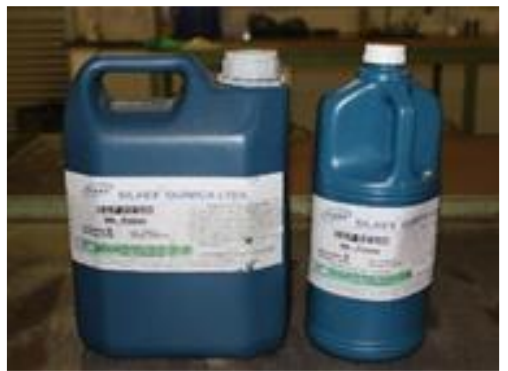

(a)

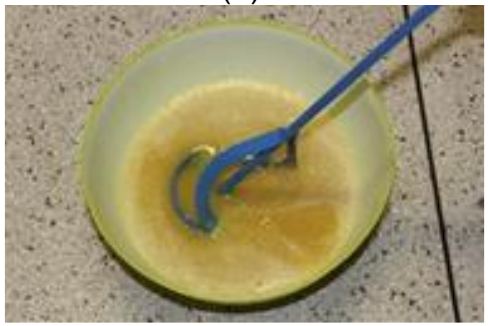

(d)

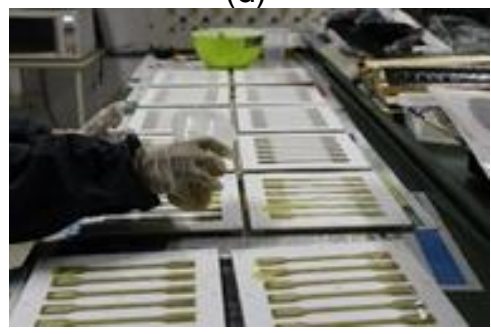

(g)

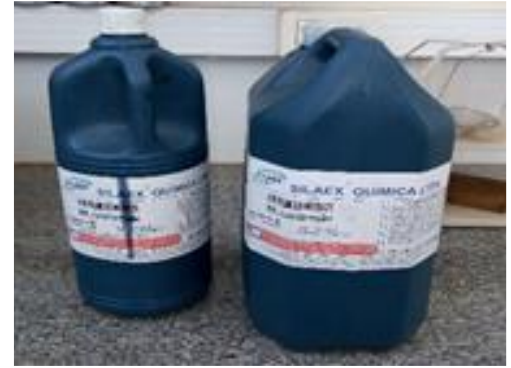

(b)

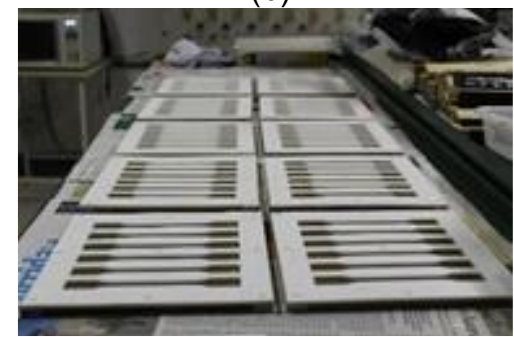

(e)

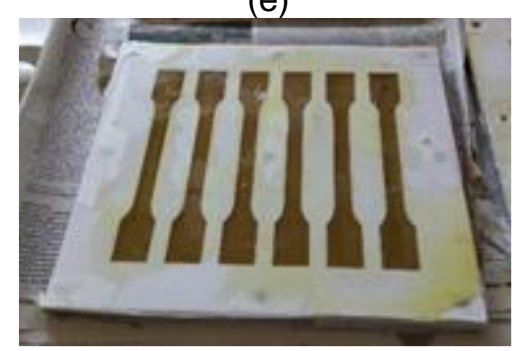

(h)

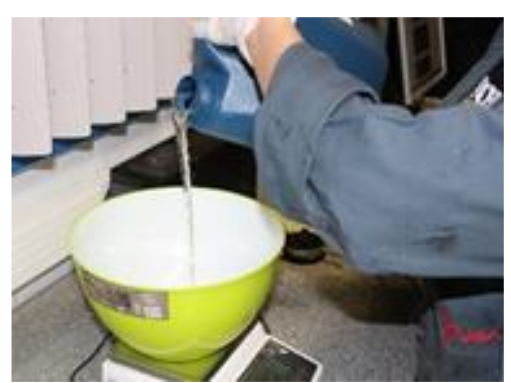

(c)

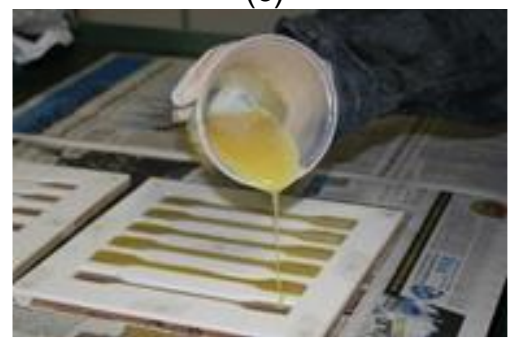

(f)

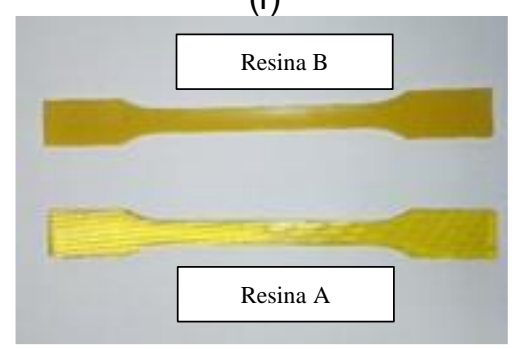

(i)

Figura 3: Resinas (a) A e (b) B, (c) pesagem dos componentes e (d) mistura mecânica, (e) moldes de teflon utilizados na moldagem dos corpos de prova de resinas epoxídicas, (f-g) lançamento da resina nos moldes de silicone, (h) corpos de prova após $24 \mathrm{~h}$ de lançamento das resinas e (i) aspecto final dos corpos de prova [15]. 

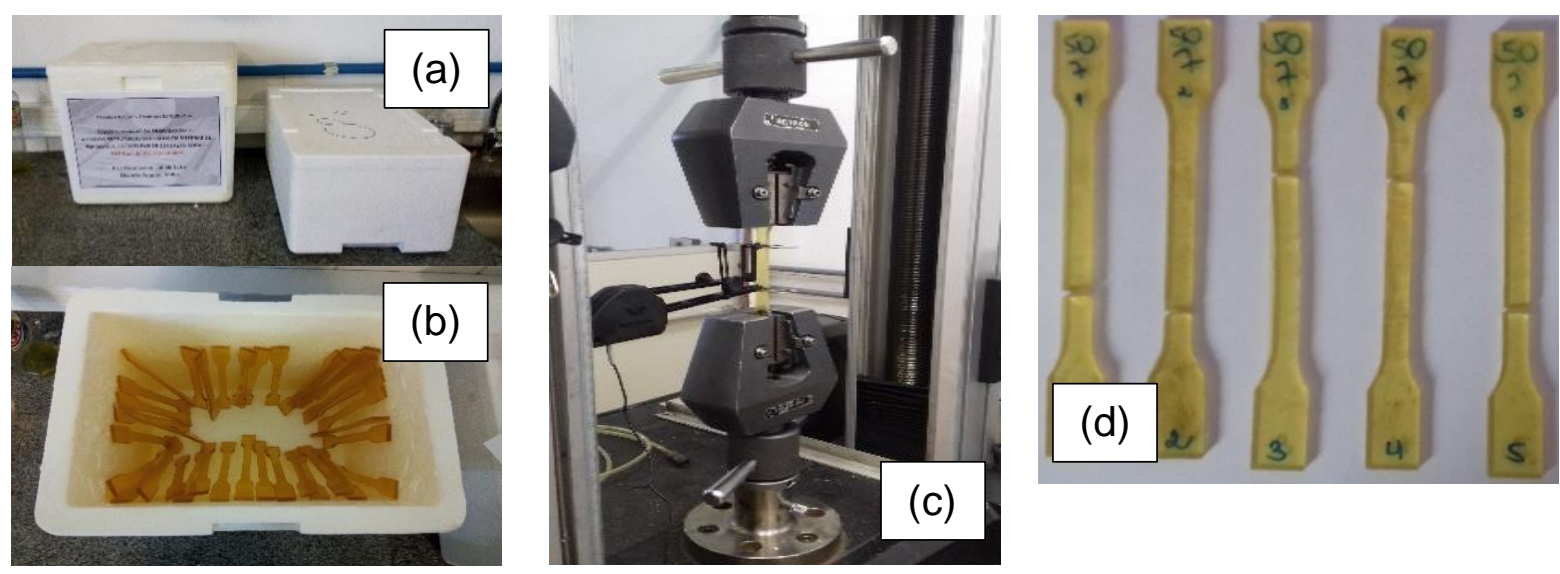

Figura 4: Ambientes de exposição interno (a) e ciclos de umidade (b), arranjo de ensaio (c) e aspecto final dos corpos de prova após ensaio (d)

- Caracterização dos materiais por meio de ensaios de tração uniaxial: Para a caracterização do comportamento à tração das resinas epoxídicas, ensaios de tração uniaxial (Figura $4 \mathrm{~b}$ ) foram realizados em conformidade com os procedimentos descritos na norma ISO 527-5 [17]. Deste modo, pelo menos 5 corpos de prova expostos aos mesmos ambientes já apresentados foram ensaiados nas idades pré-determinadas na Tabela 1. Para isso, uma máquina de ensaios universal da marca Instron, modelo 5569, com velocidade de aplicação de carga de $2 \mathrm{~mm} / \mathrm{min}$ foi utilizada.

\section{Apresentação e análise dos resultados}

A Figura 5 e a Tabela 2 apresentam o diagrama tensão versus deformação e os resultados da tensão máxima de tração e do módulo de elasticidade obtidos para os corpos de prova mantidos em ambiente protegido ou expostos a ciclos de umidade. Nesta Tabela, $\sigma_{\max }$ é a tensão de tração máxima média obtida nos ensaios, $\varepsilon_{\sigma_{\max }}$ é a deformação média registrada em $\sigma_{\max }$ e E é o módulo de elasticidade médio. As principais variáveis avaliadas são o comportamento tensão versus deformação, as alterações do módulo de elasticidade e do modo de ruptura dos corpos de prova quando submetidos aos ambientes de exposição descritos.

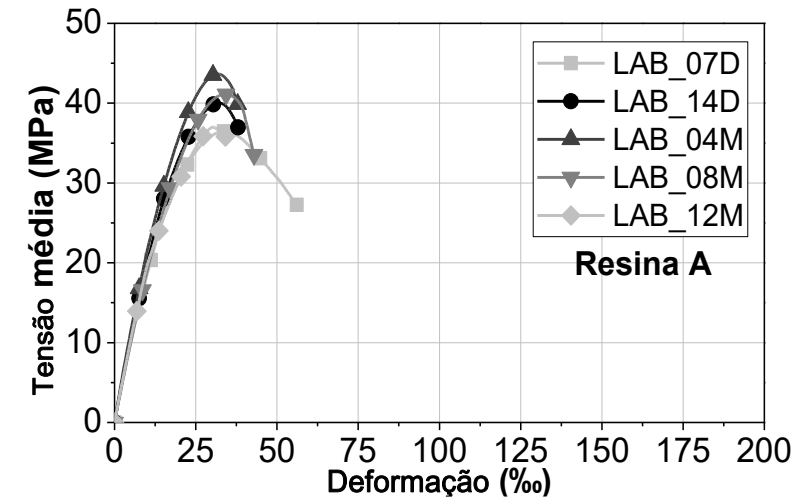

(a)

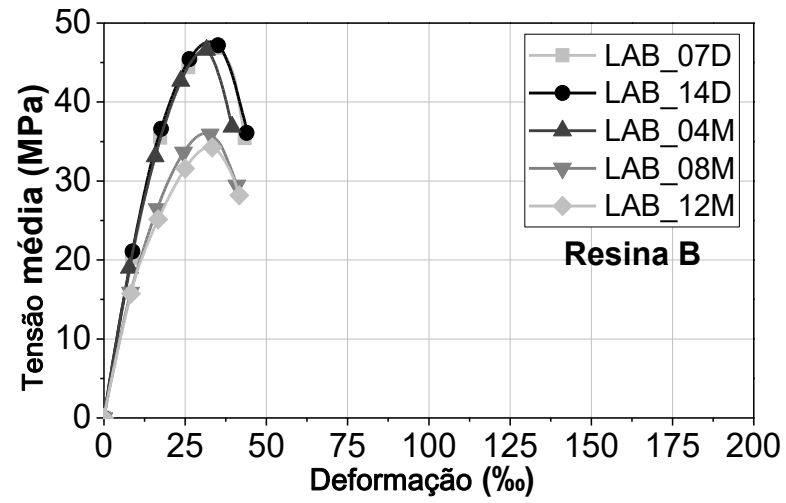

(b) 
DALFRÉ, G. M.; OLIVEIRA, M. C.; SARTI JR., L. A; ARAÚJO, C. J. V. AVALIAÇÃO DO COMPORTAMENTO DE RESINAS EPOXÍDICAS SUBMETIDAS A CICLOS DE UMIDADE. $4^{\circ}$ Simpósio Paranaense de Patologia das Construções (4 SPPC), artigo 4SPPC113, pp. 101 - 111, 2019. DOI: 10.4322/2526-7248.033

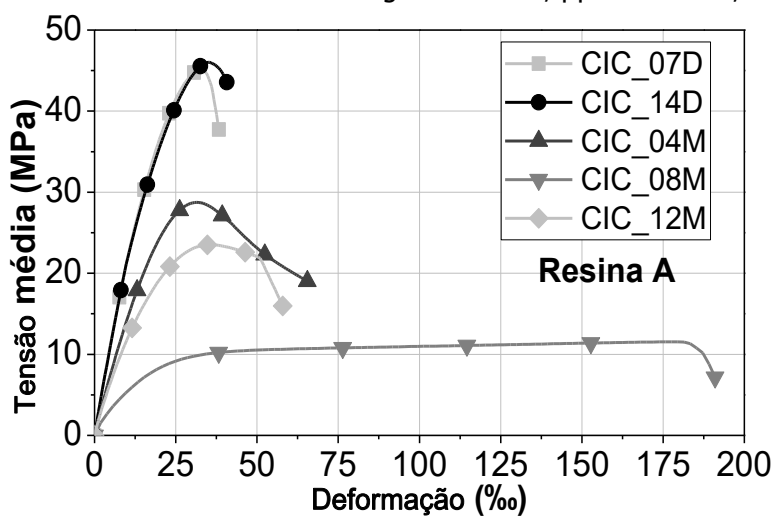

(c)

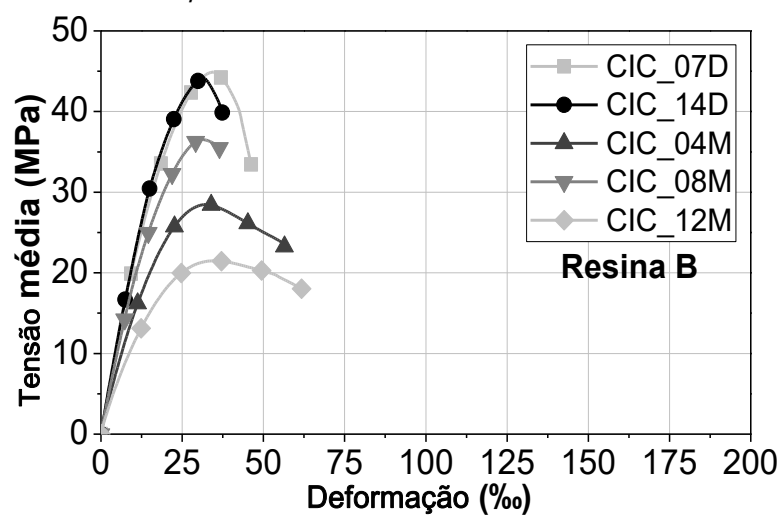

(d)

Figura 5: Diagramas tensão versus deformação dos corpos de prova mantidos em ambiente laboratorial ( $a-b)$ e em ciclos de umidade (c-d)

Tabela 2: Resumo dos resultados obtidos nos ensaios de tração uniaxial

\begin{tabular}{|c|c|c|c|c|c|c|c|c|c|c|}
\hline \multirow[b]{2}{*}{ ID } & & \multicolumn{3}{|c|}{$\sigma_{\max }$} & \multicolumn{3}{|c|}{$\varepsilon_{\sigma \max }$} & \multicolumn{3}{|c|}{$E$} \\
\hline & & $\begin{array}{l}\text { Média } \\
\text { (MPa) }\end{array}$ & $\begin{array}{l}\text { D.P. } \\
\text { (MPa) }\end{array}$ & $\operatorname{Cov}(\%)$ & $\begin{array}{l}\text { Média } \\
(\%)\end{array}$ & $\begin{array}{l}\text { D.P. } \\
(\%)\end{array}$ & $\begin{array}{l}\text { Cov } \\
(\%)\end{array}$ & $\begin{array}{l}\text { Média } \\
(\mathrm{GPa})\end{array}$ & $\begin{array}{l}\text { D.P. } \\
\text { (GPa) }\end{array}$ & $\begin{array}{l}\text { Cov } \\
(\%)\end{array}$ \\
\hline \multirow{5}{*}{$\begin{array}{c}\text { Resina A } \\
\text { Laboratório }\end{array}$} & 07D & 36,5 & 1,1 & 3,0 & 34,0 & 1,2 & 3,6 & 2,1 & 0,2 & 9,9 \\
\hline & $14 \mathrm{D}$ & 40,2 & 1,5 & 3,8 & 32,4 & 1,7 & 5,1 & 2,2 & 0,2 & 10,7 \\
\hline & $04 \mathrm{M}$ & 43,8 & 1,2 & 2,7 & 32,8 & 2,6 & 7,8 & 2,4 & 0,3 & 11,4 \\
\hline & $08 \mathrm{M}$ & 41,1 & 0,5 & 1,1 & 34,0 & 0,8 & 2,3 & 2,0 & 0,2 & 8,5 \\
\hline & $12 \mathrm{M}$ & 37,9 & 1,2 & 3,1 & 32,9 & 2,7 & 8,1 & 2,1 & 0,2 & 8,2 \\
\hline \multirow{5}{*}{$\begin{array}{l}\text { Resina A } \\
\text { Ciclos de } \\
\text { umidade }\end{array}$} & 07D & 45,2 & 1,0 & 2,3 & 33,1 & 1,3 & 4,0 & 2,3 & 0,2 & 6,6 \\
\hline & 14D & 46,2 & 1,4 & 2,9 & 35,3 & 2,0 & 5,6 & 2,3 & 0,2 & 6,6 \\
\hline & $04 \mathrm{M}$ & 28,8 & 1,5 & 5,4 & 31,7 & 0,8 & 2,6 & 1,6 & 0,1 & 4,6 \\
\hline & $08 \mathrm{M}$ & 11,6 & 1,2 & 10,4 & 180,8 & 8,5 & 4,7 & 0,7 & 0,1 & 12,3 \\
\hline & $12 \mathrm{M}$ & 23,6 & 2,5 & 10,4 & 39,3 & 2,3 & 5,8 & 1,4 & 0,2 & 14,1 \\
\hline \multirow{5}{*}{$\begin{array}{c}\text { Resina B } \\
\text { Laboratório }\end{array}$} & 07D & 47,0 & 1,0 & 2,1 & 32,9 & 0,4 & 1,4 & 2,5 & 0,2 & 6,1 \\
\hline & $14 \mathrm{D}$ & 47,7 & 1,3 & 2,8 & 32,7 & 1,4 & 4,2 & 2,6 & 0,1 & 4,7 \\
\hline & $04 \mathrm{M}$ & 46,7 & 0,5 & 1,1 & 31,8 & 1,1 & 3,4 & 2,6 & 0,1 & 4,5 \\
\hline & $08 \mathrm{M}$ & 36,3 & 2,0 & 5,5 & 31,8 & 2,5 & 7,7 & 2,1 & 0,0 & 2,1 \\
\hline & $12 \mathrm{M}$ & 34,7 & 0,6 & 1,8 & 33,1 & 3,3 & 9,9 & 2,0 & 0,3 & 12,9 \\
\hline \multirow{5}{*}{$\begin{array}{l}\text { Resina B } \\
\text { Ciclos de } \\
\text { umidade }\end{array}$} & 07D & 45,0 & 1,1 & 2,4 & 35,1 & 1,8 & 5,1 & 2,4 & 0,1 & 4,7 \\
\hline & 14D & 44,4 & 0,7 & 1,5 & 32,8 & 2,0 & 6,2 & 2,3 & 0,1 & 4,6 \\
\hline & $04 \mathrm{M}$ & 28,6 & 1,7 & 5,8 & 33,1 & 2,2 & 6,7 & 1,7 & 0,3 & 17,7 \\
\hline & $08 \mathrm{M}$ & 36,8 & 0,7 & 2,0 & 32,1 & 1,8 & 5,5 & 2,1 & 0,0 & 2,2 \\
\hline & $12 \mathrm{M}$ & 21,6 & 1,2 & 5,8 & 34,7 & 1,1 & 3,2 & 1,3 & 0,1 & 8,9 \\
\hline \multicolumn{11}{|c|}{ D.P. $=$ desvio padrão, CoV = coeficiente de variância } \\
\hline
\end{tabular}


DALFRÉ, G. M.; OLIVEIRA, M. C.; SARTI JR., L. A; ARAÚJO, C. J. V. AVALIAÇÃO DO COMPORTAMENTO DE RESINAS EPOXÍDICAS SUBMETIDAS A CICLOS DE UMIDADE. $4^{\circ}$ Simpósio Paranaense de Patologia das Construções (40 SPPC), artigo 4SPPC113, pp. $101-111$, 2019. DOI: 10.4322/2526-7248.033

Testes de análise de variância (ANOVA), seguidos de testes de Tukey para comparação de equivalência entre médias, com nível de significância de $5 \%$, foram realizados para uma interpretação mais consistente dos resultados experimentais obtidos. As análises estatísticas foram realizadas uma vez que uma observação direta apenas dos valores médios pode induzir a conclusões equivocas sobre o fenômeno estudado.

Analisando-se os resultados apresentados na Tabela 2 e a Figura 7 verifica-se que 0 módulo de elasticidade, tensões e deformações no pico obtidas para ambas as resinas e para as idades de 7 e 14 dias de cura são estatisticamente equivalentes.

Para ambas as resinas, e considerando-se como referência para a avaliação da degradação a idade de 14 dias, verifica-se grande redução das tensões de tração máximas dos corpos de prova. Com relação as deformações, estas são estaticamente equivalentes para os corpos de prova, de ambas as resinas, mantidos em laboratório. Entretanto, pela análise dos resultados, verifica-se que a Resina $A$ foi mais suscetível a presença de umidade, apresentando amolecimento da matriz para a idade de 8 meses (ensaio realizado em ciclo úmido).

Verifica-se, também, a pequena recuperação da tensão e deformação desta resina com a realização de ensaio de tração em ciclo seco (12 meses). Entretanto, tanto para a idade de 4 quanto 8 meses, verifica-se uma redução da tensão de tração e módulo de elasticidade de até $74 \%$ e $69 \%$, respectivamente, quando comparado aos resultados obtidos nos ensaios realizados aos 14 dias (referência).

A resina $B$ também apresenta redução da tensão e módulo de elasticidade quando exposta a ciclos de umidade, apresentando reduções de até $51 \%$ e $43 \%$, respectivamente, em comparação aos resultados obtidos para a idade de 14 dias.

Tais comportamento também foram verificados em trabalhos realizados por Ghorbel e Valentim [8] e Silva et al. [10] e corroboram os obtidos nesta pesquisa. Assim, verificase que a umidade provoca o enfraquecimento das ligações intermoleculares dos materiais epoxídicos resultando em redução da sua resistência e módulo de elasticidade, influenciando, também, sua deformação.

Neste sentido, tendo em vista que nas técnicas de colagem o adesivo assume função principal na aderência das mantas, laminados ou barras ao substrato de concreto, o entendimento de seu comportamento a longo prazo é de extrema importância. Para além disso verifica-se a necessidade do uso de revestimentos protetores, tais como os já indicados para sistema de reforços expostos a situações de incêndio, para mitigar o processo de degradação das resinas epoxídicas.

\section{Conclusão}

Este trabalho é baseado na análise experimental da degradação das propriedades mecânicas de resinas epoxídicas utilizadas em sistemas de reforço quando expostas a ciclos de umidade. Neste sentido, corpos de prova de resinas foram moldados e, após 14 dias de idade, mantidos em ambiente protegido ou expostos a ciclos de umidade e posteriormente ensaiados nas idades de 4, 8 e 12 meses. Com base nos resultados obtidos verificou-se uma redução significativa das tensões de tração e módulo de 
DALFRÉ, G. M.; OLIVEIRA, M. C.; SARTI JR., L. A; ARAÚJO, C. J. V. AVALIAÇÃO DO COMPORTAMENTO DE RESINAS EPOXÍDICAS SUBMETIDAS A CICLOS DE UMIDADE. $4^{\circ}$ Simpósio Paranaense de Patologia das Construções (40 SPPC), artigo 4SPPC113, pp. $101-111$, 2019. DOI: 10.4322/2526-7248.033

elasticidade após exposição aos ciclos de umidade. A resina A (primer) apresentou redução da tensão de tração e módulo de elasticidade de até $74 \%$ e $69 \%$, respectivamente, quando comparado aos resultados obtidos nos ensaios realizados aos 14 dias (referência). Para além disso, verificou-se o amolecimento da matriz para a idade de 8 meses. A resina B (laminação) apresentou reduções de até $51 \%$ e $43 \%$ da tensão máxima e módulo de elasticidade, respectivamente, quando exposta a ciclos de umidade. Assim, justifica-se a necessidade do entendimento do comportamento a longo prazo dos materiais utilizados em sistemas de reforço, assim como do uso de sistemas protetores.

\section{Referências}

[1] HOLLAWAY, L. (1993). Polymer Composites for Civil and Structural Engineering. Chapman \& Hall, Glasgow.

[2] MACHADO, A. P.; MACHADO, B. A. (2015). Reforço de estruturas de concreto armado com sistemas compostos FRP. São Paulo: Pini.

[3] ISIS (2006). Durability of FRP Composites for Construction: Educational Module no.8:, The Canadian Network of Centers of Excellence on Intelligent Sensing for Innovative Structures, ISIS Canada Corporation, Manitoba, Canada.

[4] SOUZA, V. C.; RIPPER, T. Patologia, recuperação e reforço de estruturas de concreto. São Paulo: Pini, 1998. 255 p.

[5] SILVA, P. M. (2017). Time-dependent behavior and durability of RC slabs strengthened with NSM CFRP strips. Thesis, Universidade do Minho, Portugal.

[6] HELBLING, C.; KARBHARI, V. M. (2017). Durability of composites in aqueous environments. In: Durability of Composites for Civil Structural Applications, USA: CRC Press, 2007.

[7] WEITSMAN, Y.J.; ELAHI, M. (2000). Effects of fluids on deformation, strength and durability of polymeric composites - an overview. Mechanics of time-dependent materials, v.4, p.107-126.

[8] GHORBEL, I.; VALENTIN, D. (1994). Hydrothermal effects on the physico-chemical properties of pure and glass fiber reinforced polyester and vinylester resins. Polymer Composites, v.14, n.4, p.324-334, 1994.

[9] YANG, Q.; GUIJUN, X.; KARBHARI, V. (2008). Hygrothermal ageing of an epoxy adhesive used in FRP strengthening of concrete. Journal of Applied Polymer Science, v.107, n.4, p. 2607-2617, 2008.

[10] SILVA, P.; FERNANDES, P.; SENA-CRUZ, J.; XAVIER, J.; CASTRO, F.; SOARES, D.; CARNEIRO, V. (2016). Effects of different environmental conditions on the mechanical characteristics of a structural epoxy. Composites Part B., v.88, p.55-63.

[11] ABANILLA, M.A.; LI, Y.; KARBHARI, V. M. (2005). Durability characterization of wet layup grafite/epoxy composites used in external strengthening. Composites Part B, v.37, p. 200-212.

[12] BENZARTI, K.; CHATAIGNER, S.; QUIERTANT, M.; MARTY, C.; AUBAGNAC, C. (2011). Accelerated ageing behavior of the adhesive bond between concrete specimens and CFRP overlays. Construction and Building Materials, v.25, p.523-538. 
DALFRÉ, G. M.; OLIVEIRA, M. C.; SARTI JR., L. A; ARAÚJO, C. J. V. AVALIAÇÃO DO COMPORTAMENTO DE RESINAS EPOXÍDICAS SUBMETIDAS A CICLOS DE UMIDADE. $4^{\circ}$ Simpósio Paranaense de Patologia das Construções (40 SPPC), artigo 4SPPC113, pp. $101-111$, 2019. DOI: 10.4322/2526-7248.033

[13] Ferreira, D. C. (2019). Durabilidade de vigas de concreto armado reforçadas com mantas de CFRP. Dissertação. Programa de Pós-Graduação em Engenharia Civil. Universidade Federal de São Carlos. São Carlos.

[14] Oliveira, M. C. (2019). Análise do Comportamento Estrutural e Durabilidade de Pilares de Concreto Armado Reforçados com Manta de GFRP. Dissertação. Programa de Pós-Graduação em Engenharia Civil. Universidade Federal de São Carlos. São Carlos.

[15] ESCOBAL, A. D.; DALFRÉ, G. M. (2017). Caracterização da degradação de adesivos estruturais utilizados em sistemas de reforço de estrutura de concreto armado. Relatório científico de progresso. Projeto FAPESP - Processo 2016/200256. São Carlos, SP.

[16] INTERNATIONAL ORGANIZATION FOR STANDARDIZATION. ISO 527-2: Plastics - determination of tensile properties - Part 2: test conditions for moulding and extrusion plastics. Geneva, Switzerland, 5 pp, 2012.

[17] INTERNATIONAL ORGANIZATION FOR STANDARDIZATION. ISO 527-5: Plastics - determination of tensile properties - Part 5: Test conditions for unidirectional fibre-reinforced plastic composites. Geneva, Switzerland, 5 pp, 2012. 